\title{
An Optimization Model for Design of Asphalt Pavements Based on IHAP Code Number 234
}

\author{
Ali Reza Ghanizadeh \\ Department of Civil Engineering, Sirjan University of Technology, Sirjan 78137, Iran \\ Correspondence should be addressed to Ali Reza Ghanizadeh; ghanizadeh@sirjantech.ac.ir
}

Received 6 November 2015; Revised 7 January 2016; Accepted 12 January 2016

Academic Editor: Samer Madanat

Copyright (C) 2016 Ali Reza Ghanizadeh. This is an open access article distributed under the Creative Commons Attribution License, which permits unrestricted use, distribution, and reproduction in any medium, provided the original work is properly cited.

Pavement construction is one of the most costly parts of transportation infrastructures. Incommensurate design and construction of pavements, in addition to the loss of the initial investment, would impose indirect costs to the road users and reduce road safety. This paper aims to propose an optimization model to determine the optimal configuration as well as the optimum thickness of different pavement layers based on the Iran Highway Asphalt Paving Code Number 234 (IHAP Code 234). After developing the optimization model, the optimum thickness of pavement layers for secondary rural roads, major rural roads, and freeways was determined based on the recommended prices in "Basic Price List for Road, Runway and Railway" of Iran in 2015 and several charts were developed to determine the optimum thickness of pavement layers including asphalt concrete, granular base, and granular subbase with respect to road classification, design traffic, and resilient modulus of subgrade. Design charts confirm that in the current situation (material prices in 2015), application of asphalt treated layer in pavement structure is not cost effective. Also it was shown that, with increasing the strength of subgrade soil, the subbase layer may be removed from the optimum structure of pavement.

\section{Introduction}

Surface transportation is the most widely used mode of transportation, and pavements are an essential part of roads, streets, and parking lots in all over the world. The development of a country is often judged in terms of its total paved road. Like other engineered structures, designed pavements are expected to be adequately strong and durable for their design life. They are expected to function properly by providing a smooth traveling surface for the traffic under various conditions of the environment. In order to ensure this, pavements must be designed, constructed, maintained, and managed properly [1].

Pavements can be mainly classified into flexible and rigid pavements. The wearing layer, which is in contact with the traffic, is an asphalt mix in case of flexible pavements and Portland cement concrete in case of rigid pavements.

Methods for design of flexible pavements can be classified into five main categories as follows [2]:

(1) empirical method with or without a soil strength test,

(2) limiting shear failure method,
(3) limiting deflection method,

(4) regression method based on pavement performance or road test,

(5) mechanistic-empirical method.

The concept of mechanistic-empirical pavement design was firstly introduced in the 1960s [3,4]. This method is used nowadays by many countries and institutions for the design of flexible pavements [5-11]. However, due to the need for equipped labs and because extensive research is still needed for the use of mechanistic-empirical method, only empirical methods are used for pavement design in many countries [1215].

Flexible pavements design in Iran commonly is accomplished by method presented in Iranian Highway Asphalt Paving Code Number 234 (IHAP Code 234). This method is categorized as a regression method and has been adopted with minor changes from AASHTO 1993 pavement design method. Flexible pavement design, using AASHTO method, is based on studies and tests that AASHTO carried out in Ottawa and Illinois between the years 1958 and 1960. 
The first AASHTO pavement design manual was published in 1961 and revised in 1972 and 1981. Again, during the years 1984 and 1985, a committee, consisting of AASHTO experts and some consultant engineers, revised it under NCHRP 207/24 Project and, after some modifications, presented the 1986 AASHTO pavement design manual [2]. Then in 1993 the method was revised again and led to the publication of the 1993 version of the manual. Equations proposed in AASHTO 1993 have some significant limitations, because these equations were developed for the specific conditions of the AASHO Road Test. These limitations are as follows.

(i) The equations are only valid in case of the specific pavement materials and roadbed soil of the AASHO Road Test.

(ii) The equations are only valid in case of environmental conditions at the AASHO Road Test.

(iii) The developed equations are based on a two-year testing period rather than a long period. Therefore, it is difficult to extrapolate environmental factors to a longer period.

(iv) The traffic was about one million equivalent single axle load (ESAL) and tires inflated to 70 psi.

Despite all the abovementioned limitations, Iran Highway Asphalt Paving Code Number 234 has been proposed for design of flexible pavements in all conditions [15]. Also, due to the lack of information about life-cycle cost parameters in Iran, life cycle analysis has not been considered in Iran Highway Asphalt Paving Code Number 234 and design of flexible pavements is commonly fulfilled by considering construction costs only.

Researchers proposed different models and approaches for optimum design of flexible pavement structures. Rouphail proposed a mixed-integer programming model to identify the number, type, and thicknesses of paving materials required to meet the structural strength requirements of the pavement system at a minimum initial cost [16]. Nicholls presented an optimization program supplement to the DNPS86 pavement design computer program to produce a minimumcost combination of pavement layer thicknesses. This method enables the obtaining of the least cost design for flexible and rigid pavements without manual iteration [17]. Mamlouk et al. developed a project-level optimization approach to minimize total pavement cost within an analysis period [18]. This approach enables the designer to select the optimum initial pavement thickness, overlay thickness, and overlay timing. The developed model combined the AASHTO design procedure and the mechanistic multilayer elastic solution. $\mathrm{Mu}-\mathrm{yu}$ and Shao-yi proposed an optimization model for design of flexible pavements based on fatigue and rutting performance [19]. They used genetic algorithms (GAs) to solve the optimization model. Abaza and Abu-Eisheh represented an optimum approach for the design of flexible pavements based on AASHTO method which utilized the anticipated performance of pavement and its life-cycle cost. They showed that pavements should be designed for higher terminal serviceability index values than currently recommended [20]. Ouyang and Madanat presented a mixed-integer nonlinear programming for optimal highway pavement rehabilitation planning which minimizes the life-cycle cost during design period [21]. Fakhri and Ghanizadeh developed an optimization model to determine the optimum structure and thickness of pavement layers, based on the AASHTO method [22]. The proposed model, in the form of a linear programming model, could determine the optimum configuration of pavement layers as well as optimum thickness of pavement layers. It could only consider the optimum structure of pavements consisting of asphalt, granular base, and granular subbase layers. Proposed model did not consider the treated base layers in pavement structure. Also, by employing this model, thickness of layers was determined as real numbers not integer numbers which should be revised for application in construction stage. Sanchez-Silva et al. present a model for reliability cost-based optimization of asphalt pavement structures based on both economic and operation considerations [23]. The proposed model considered the fatigue damage caused on the asphalt surface and the degradation of granular materials caused by repetitive loading cycles. They showed that the reliability based design optimization combined with a long-term maintenance policy of pavements produces appropriate integral designs. Rajbongshi and Das presented a simple methodology to assist a pavement designer in selecting an optimal pavement design thickness which is cost effective yet does not compromise the reliability of the pavement design [24]. They developed pavement design charts as an illustrative example to explain how the proposed methodology can be considered as an improvement over the deterministic design. Santos and Ferreira proposed a pavement design optimization model, called OPTIPAV, which considers pavement performance, construction costs, maintenance and rehabilitation costs, user costs, the residual value of the pavement at the end of the project analysis period, and preventive maintenance and rehabilitation interventions [25].

In this paper, an optimization model was proposed to determine the optimum structure of pavement as well as the thickness of each layer, based on minimizing the initial construction cost of pavement. Also several charts were developed to determine the optimum thickness of pavement layers with respect to road classification, design traffic, and strength of subgrade soil. The proposed optimization method in this research considers stabilized layers in optimization model. Also optimization problem was modeled as an integer programming model.

\section{Pavement Design Using IHAP Code 234}

Equation (1) shows the basic equation for design of flexible pavements using IHAP Code 234 [15]:

$$
\begin{aligned}
\log W_{8.2}= & Z_{R} S_{0}+9.36 \log (\mathrm{SN}+1)-0.2 \\
& +\frac{\log (\Delta \mathrm{PSI} /(4.2-1.5))}{0.4+1094 /(\mathrm{SN}+1)^{5.19}} \\
& +2.3 \log \left(\frac{M_{r}}{0.07}\right)-8.07
\end{aligned}
$$


TABLE 1: Design parameters for different class of roads [15].

\begin{tabular}{lcccc}
\hline Class of road & Reliability & Standard normal deviate $\left(Z_{R}\right)$ & $S_{0}$ & $P_{i}$ \\
\hline Expressways and freeways & 90 & -1.282 & 0.35 & 4.2 \\
Major rural roads & 80 & -0.841 & 0.35 & 4.2 \\
Secondary rural roads (2nd class) & 70 & -0.524 & 0.35 & 4.2 \\
\hline
\end{tabular}

where $W_{8.2}$ is predicted number of $80 \mathrm{kN}$ single axel load applications, $Z_{R}$ is standard normal deviate, $S_{0}$ is combined standard error of traffic prediction and performance prediction, $\triangle \mathrm{PSI}$ is difference between initial design serviceability index $\left(P_{0}\right)$ and terminal design serviceability index $\left(P_{t}\right)$, and $M_{r}$ is resilient modulus $\left(\mathrm{kg} / \mathrm{cm}^{2}\right)$.

In this equation all the parameters are known except the pavement structural number (SN). So, it is possible to find the value of SN by solving (1) using iteration method. It can also be solved with the help of existing graphs.

Design parameters dictated by IHAP Code 234 for design of flexible pavements for different class of roads are given in Table 1.

After finding $\mathrm{SN}$, it is possible to find the thickness of each layer by converting $\mathrm{SN}$ to real thickness of the constituent layers. The thickness of each layer should be found so that the following equation can be totally satisfied:

$$
\mathrm{SN}=\frac{1}{2.5}\left(a_{1} d_{1}+m_{2} a_{2} d_{2}+m_{3} a_{3} d_{3}+\cdots+m_{n} a_{n} d_{n}\right),
$$

where $m_{i}$ is $i$ th layer drainage coefficient. $a_{i}$ is $i$ th layer coefficient. $d_{i}$ is $i$ th layer thickness $(\mathrm{cm})$.

The layer coefficient for an asphalt concrete layer with resilient modulus of $31500 \mathrm{~kg} / \mathrm{cm}^{2}$ can be assumed as 0.44 . Equations (3) and (4) can be used for determination of the layer coefficients for granular base and granular subbase layers, respectively,

$$
\begin{aligned}
& a_{\mathrm{GB}}=0.249 \log _{10}\left(\frac{M_{r_{\mathrm{GB}}}}{0.07}\right)-0.977, \\
& a_{\mathrm{GSB}}=0.227 \log _{10}\left(\frac{M_{r_{\mathrm{GSB}}}}{0.07}\right)-0.839,
\end{aligned}
$$

where $M_{r \mathrm{~GB}}$ is the resilient modulus of granular base layer and $M_{r \mathrm{GSB}}$ is the resilient modulus of granular subbase layer in $\mathrm{kg} / \mathrm{cm}^{2}$.

In this study, the following regression equations were developed to determine the layer coefficient and resilient modulus of different layers based on charts presented in IHAP Code 234 and AASHTO 1993.

Asphalt concrete is as follows:

$$
\begin{aligned}
a_{\mathrm{AC}} & =0.16727 \ln \left(M_{r_{\mathrm{AC}}}\right)-1.29682, \\
M_{r_{\mathrm{AC}}} & =33.511268 \mathrm{Marshal}_{\mathrm{AC}}-326.00433 .
\end{aligned}
$$

Asphalt treated base is as follows:

$$
\begin{aligned}
a_{\mathrm{ATB}}= & 0.1419 \ln \left(M_{r_{\mathrm{ATB}}}\right)-1.13175, \\
M_{r \text { ATB }}= & 0.014391\left(\mathrm{Marshal}_{\mathrm{ATB}}\right)^{2} \\
& +14.969313 \mathrm{Marshal}_{\mathrm{ATB}}+5295.655843 .
\end{aligned}
$$

Cement treated base is as follows:

$$
\begin{aligned}
& a_{\text {СТВ }}=0.2108 \ln \left(M_{r \text { СТВ }}\right)-2.08733, \\
& a_{\text {СТВ }}=0.00224 \mathrm{CS}_{\text {СТВ }}+0.0935 .
\end{aligned}
$$

Granular base is as follows:

$$
M_{r \mathrm{~GB}}=299.73347 \times \mathrm{CBR}_{\mathrm{GB}}^{0.43023} .
$$

Granular subbase is as follows:

$$
M_{r \mathrm{GSB}}=391.5423 \times \mathrm{CBR}_{\mathrm{GSB}}^{0.28552} .
$$

Subgrade soil is as follows:

$$
M_{r \mathrm{SG}}=134.79525 \times \mathrm{CBR}_{\mathrm{SG}}^{0.6846}
$$

where $M_{r}$ denotes resilient modulus in $\mathrm{kg} / \mathrm{cm}^{2}$, Marshal denotes marshal stability of asphalt mix materials in $\mathrm{kg}, a$ denotes layer coefficient, and CS denotes 7 days compressive strength $\left(\mathrm{kg} / \mathrm{cm}^{2}\right)$ of cement treated materials. In case of all developed equations, the coefficient of determination $\left(R^{2}\right)$ was more than 0.98 .

Not only should (2) be satisfied but also the thickness of each layer should be such that the total compressive stress, applied on lower layers, be reduced to the tolerable stress of these layers. To this end, the following equations should be satisfied

$$
\begin{aligned}
a_{1} \cdot d_{1} & \geq 2.5 \mathrm{SN}_{1}, \\
a_{1} \cdot d_{1}+m_{2} \cdot a_{2} \cdot d_{2} & \geq 2.5 \mathrm{SN}_{2}, \\
a_{1} \cdot d_{1}+m_{2} \cdot a_{2} \cdot d_{2}+m_{3} \cdot a_{3} \cdot d_{3} & \geq 2.5 \mathrm{SN}_{3} .
\end{aligned}
$$

In these equations, $\mathrm{SN}_{1}, \mathrm{SN}_{2}$, and $\mathrm{SN}_{3}$ are the structural number of granular base, granular subbase, and subgrade layers, respectively. Their values are found from (1) with the only difference that instead of resilient modulus of subgrade soil, resilient modulus of granular base is used to find $\mathrm{SN}_{1}$ and resilient modulus of granular subbase is used to find $\mathrm{SN}_{2}$. Also, the thickness of asphalt concrete layer and granular base layer should not be taken less than those given in Table 2, considering the construction thickness. For the granular subbase layer, the minimum thickness should be considered as $15 \mathrm{~cm}$. 
TABLE 2: Minimum thickness for asphalt concrete and granular base [15].

\begin{tabular}{lcc}
\hline Traffic $($ ESAL) & Asphalt concrete $(\mathrm{cm})$ & Granular base $(\mathrm{cm})$ \\
\hline Less than 150000 & 5 & 10 \\
$150000-500000$ & 6 & 10 \\
$500000-2000000$ & 8 & 15 \\
$2000000-7000000$ & 9 & 15 \\
Greater than 7000000 & 10 & 15 \\
\hline
\end{tabular}

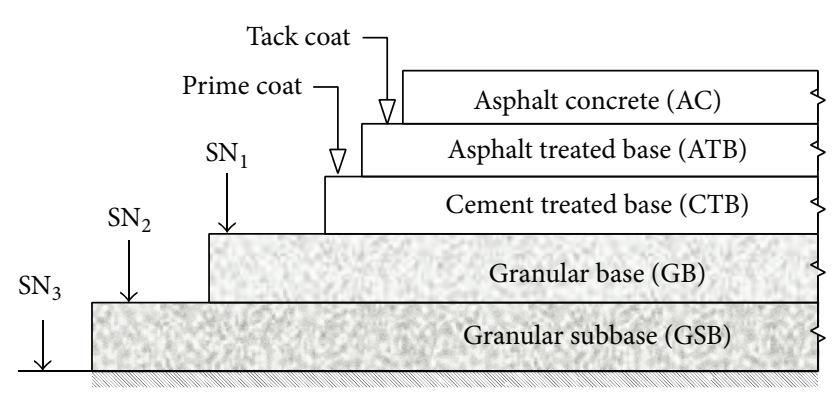

Subgrade soil

FIGURE 1: Assumed structure of pavement for optimization.

\section{Optimal Design of Flexible Pavements Based on IHAP Code 234}

Considering a six-layer pavement system as shown in Figure 1, the integer programming model to find the optimum structural configuration as well as optimum thickness of each layer can be written as follows.

\section{Objective Function. Consider}

Min $Z$

$$
\begin{gathered}
=C_{\mathrm{AC}} \cdot d_{\mathrm{AC}}+E_{\mathrm{ATB}} \cdot C_{\mathrm{ATB}} \cdot d_{\mathrm{ATB}} \\
+\frac{E_{\mathrm{CTB}} \cdot C_{\mathrm{CTB}} \cdot d_{\mathrm{CTB}}}{100}+\frac{C_{\mathrm{GB}} \cdot d_{\mathrm{GB}}}{100} \\
+\frac{C_{\mathrm{GSB}} \cdot d_{\mathrm{GSB}}}{100}+E_{\mathrm{ATB}} \cdot C_{\mathrm{TC}} \cdot Q_{\mathrm{TC}} .
\end{gathered}
$$

\section{Constraints}

Van Tile Constraints. Consider

$$
\begin{aligned}
& a_{\mathrm{AC}} \cdot d_{\mathrm{AC}}+E_{\mathrm{ATB}} \cdot a_{\mathrm{ATB}} \cdot d_{\mathrm{ATB}}+E_{\mathrm{CTB}} \cdot a_{\mathrm{CTB}} \\
& \cdot d_{\mathrm{CTB}} \geq 2.5 \mathrm{SN}_{1} \cdot E_{\mathrm{GB}}, \\
& a_{\mathrm{AC}} \cdot d_{\mathrm{AC}}+E_{\mathrm{ATB}} \cdot a_{\mathrm{ATB}} \cdot d_{\mathrm{ATB}}+E_{\mathrm{CTB}} \cdot a_{\mathrm{CTB}} \cdot d_{\mathrm{CTB}} \\
& +E_{\mathrm{GB}} \cdot m_{\mathrm{GB}} \cdot a_{\mathrm{GB}} \cdot d_{\mathrm{GB}} \geq 2.5 \mathrm{SN}_{2} \cdot E_{\mathrm{GSB}}, \\
& a_{\mathrm{AC}} \cdot d_{\mathrm{AC}}+E_{\mathrm{ATB}} \cdot a_{\mathrm{ATB}} \cdot d_{\mathrm{ATB}}+E_{\mathrm{CTB}} \cdot a_{\mathrm{CTB}} \cdot d_{\mathrm{CTB}} \\
& +E_{\mathrm{GB}} \cdot m_{\mathrm{GB}} \cdot a_{\mathrm{GB}} \cdot d_{\mathrm{GB}}+E_{\mathrm{GSB}} \cdot m_{\mathrm{GSB}} \cdot a_{\mathrm{GSB}} \\
& \cdot d_{\mathrm{GSB}} \geq 2.5 \mathrm{SN}_{3}, \\
& d_{\mathrm{AC}} \geq \min _{d_{\mathrm{AC}}},
\end{aligned}
$$

$$
\begin{aligned}
& d_{\mathrm{ATB}} \geq E_{\mathrm{ATB}} \cdot \min _{d_{\mathrm{ATB}}}, \\
& d_{\mathrm{CTB}} \geq E_{\mathrm{CTB}} \cdot \min _{d_{\mathrm{CTB}}}, \\
& d_{\mathrm{GB}} \geq E_{\mathrm{GB}} \cdot \min _{d_{\mathrm{GB}}}, \\
& d_{\mathrm{GSB}} \geq E_{\mathrm{GSB}} \cdot \min _{d_{\mathrm{GSB}}} .
\end{aligned}
$$

Decision Variables. Consider

$$
\begin{array}{r}
d_{\mathrm{AC}}, d_{\mathrm{ATB}}, d_{\mathrm{CTB}}, d_{\mathrm{GB}}, d_{\mathrm{GSB}}=\text { integer, } \\
E_{\mathrm{ATB}}, E_{\mathrm{CTB}}, E_{\mathrm{GB}}, E_{\mathrm{GSB}}=\text { binery. }
\end{array}
$$

Consider the following:

$Z$ is construction cost of one square meter of pavement;

$d_{\mathrm{AC}}$ is thickness of asphalt concrete layer $(\mathrm{cm})$;

$d_{\mathrm{ATB}}$ is thickness of asphalt treated base layer $(\mathrm{cm})$;

$d_{\text {СТВ }}$ is thickness of cement treated base layer $(\mathrm{cm})$;

$d_{\mathrm{GB}}$ is thickness of granular base layer $(\mathrm{cm})$;

$d_{\mathrm{GSB}}$ is thickness of granular subbase layer $(\mathrm{cm})$;

$Q_{\mathrm{TC}}$ is quantity of tack coat for bounding asphalt concrete layer to asphalt treated base layer $\left(\mathrm{kg} / \mathrm{m}^{2}\right)$;

$a_{\mathrm{AC}}$ is layer coefficient of asphalt concrete material;

$a_{\mathrm{ATB}}$ is layer coefficient of asphalt treated base material;

$a_{\mathrm{CTB}}$ is layer coefficient of cement treated base material;

$a_{\mathrm{GB}}$ is layer coefficient of asphalt granular base material;

$a_{\mathrm{GSB}}$ is layer coefficient of granular subbase material; $C_{\mathrm{AC}}$ is construction cost of one square meter of asphalt concrete material having a thickness of $1 \mathrm{~cm}$;

$C_{\mathrm{ATB}}$ is construction cost of one square meter of asphalt treated base material having a thickness of $1 \mathrm{~cm}$ thickness;

$C_{\mathrm{CTB}}$ is construction cost of one cubic meter of cement treated base material;

$C_{\mathrm{GB}}$ is construction cost of one cubic meter of granular base material;

$\mathrm{C}_{\mathrm{GSB}}$ is construction cost of one cubic meter of granular subbase material;

$C_{\mathrm{TC}}$ is construction cost of one kilogram of tack coat material;

$E_{\mathrm{ATB}}$ is variable indicating the presence or absence of the asphalt treated base layer in the optimal structure of the pavement; $E_{\mathrm{ATB}}=1$ means the presence and $E_{\mathrm{ATB}}=0$ means the absence of the asphalt treated base layer; 
$E_{\mathrm{CTB}}$ is variable indicating the presence or absence of the cement treated base layer in the optimal structure of the pavement; $E_{\text {Ств }}=1$ means the presence and $E_{\text {Ств }}=0$ means the absence of the asphalt treated base layer;

$E_{\mathrm{GB}}$ is variable indicating the presence or absence of the granular base layer in the optimal structure of the pavement; $E_{\mathrm{GB}}=1$ means the presence and $E_{\mathrm{GB}}=0$ means the absence of the granular base layer;

$E_{\mathrm{GSB}}$ is variable indicating the presence or absence of the granular subbase layer in the optimal structure of the pavement; $E_{\mathrm{GSB}}=1$ means the presence and $E_{\mathrm{GSB}}=0$ means the absence of the granular subbase layer;

$\min _{d_{\mathrm{AC}}}$ is minimum thickness of asphalt concrete layer $(\mathrm{cm})$;

$\min _{d_{\text {ATB }}}$ is minimum thickness of asphalt treated base layer $(\mathrm{cm})$;

$\min _{d_{\text {СТB }}}$ is minimum thickness of cement treated base layer $(\mathrm{cm})$;

$\min _{d_{\mathrm{GB}}}$ is minimum thickness of granular base layer $(\mathrm{cm})$;

$\min _{d_{\mathrm{GSB}}}$ is minimum thickness of granular subbase layer $(\mathrm{cm})$.

Constraints (13) to (15) are related to maximum allowable compressive stress on granular base, granular subbase, and subgrade layers, respectively. Constraints (16) to (20) represent the constraints for the minimum construction thickness of different layers.

According to Figure 1, if an asphalt treated base layer is used in the pavement structure, application of an additional tack coating becomes necessary; presence of $E_{\mathrm{ATB}} \cdot C_{\mathrm{TC}} \cdot Q_{\mathrm{TC}}$ term in the objective function reflects the additional cost in this case.

\section{Solving the Optimization Model}

A careful study of the model shows that the presence of some terms such as $E \cdot d$ obtained from the multiplication of two unknown decision variables converts the optimization model to a nonlinear optimization model. In fact some terms in the objective function and constraints are in the form of product of two unknown decision variables (the thickness of the layer multiplied by the variable indicating the presence or absence of layer).

It is obvious that the value of variables $(E)$ can only be equal to zero or one. So, in order to convert this nonlinear model to a linear model, once the value of the variable $(E)$ is assumed to be equal to zero (the obscene of the desired layer in optimal configuration of pavement) and once the value of the variable $(E)$ is assumed to be equal to one (the presence of the desired layer in optimal configuration of pavement) and in each case, the objective function and constraints are written and the resulting integer programming model is solved. Then it is possible to find the optimum configuration
TABLE 3: Different alternatives for pavement structure.

\begin{tabular}{lccccc}
\hline Structure & \multicolumn{5}{c}{ Layers in pavement structure } \\
number & HMA & ATB & CTB & Granular base & Granular subbase \\
\hline 1 & $\checkmark$ & $\checkmark$ & $\checkmark$ & $\checkmark$ & $\checkmark$ \\
2 & $\checkmark$ & $\checkmark$ & & $\checkmark$ & $\checkmark$ \\
3 & $\checkmark$ & $\checkmark$ & & $\checkmark$ & \\
4 & $\checkmark$ & $\checkmark$ & & & $\checkmark$ \\
5 & $\checkmark$ & $\checkmark$ & & & \\
6 & $\checkmark$ & & $\checkmark$ & $\checkmark$ & $\checkmark$ \\
7 & $\checkmark$ & & $\checkmark$ & $\checkmark$ & \\
8 & $\checkmark$ & & $\checkmark$ & & \\
9 & $\checkmark$ & & $\checkmark$ & & \\
10 & $\checkmark$ & $\checkmark$ & $\checkmark$ & & \\
11 & $\checkmark$ & $\checkmark$ & $\checkmark$ & $\checkmark$ & $\checkmark$ \\
12 & $\checkmark$ & $\checkmark$ & $\checkmark$ & & $\checkmark$ \\
13 & $\checkmark$ & & & $\checkmark$ & \\
14 & $\checkmark$ & & & $\checkmark$ & \\
15 & $\checkmark$ & & & & \\
16 & $\checkmark$ & & & & \\
\hline
\end{tabular}

as well as thicknesses of pavement by comparison between the construction cost of different alternatives.

In fact, four layers including asphalt treated base (ATB), cement treated base (CTB), granular base, and granular subbase can be considered or not considered in the pavement structure and by combination of these alternatives, total of 16 alternatives for structural configuration of pavement is achieved. Possible structures for pavement are shown in Table 3. According to this method, the integer programming model is written and solved for each possible case of pavement configuration (total of 16 pavement configurations) and finally optimal configuration of pavement structure as well as the optimal thickness of each layer will be determined based on the minimum cost among 16 alternatives.

\section{Developing Design Charts}

In order to develop pavement design charts for different classes of road, including freeways and expressways, major roads, and secondary roads with respect to the current price of pavement materials in Iran, the proposed optimization model was solved by assuming different levels of design traffic and strengths of subgrade soil. Design parameters and price of pavement materials for developing design charts are given in Tables 4 and 5, respectively. Application of CTB layer is not common in practice in Iran and no specific cost has been provided for construction of this material in "Basic Price List for Road, Runway and Railway.” For this reason, CTB layer was excluded for developing design charts $\left(H_{\mathrm{CTB}}=0\right)$.

For developing design charts, the resilient modulus of subgrade soil was assumed between 200 and $1000 \mathrm{~kg} / \mathrm{cm}^{2}$ with increments of $100 \mathrm{~kg} / \mathrm{cm}^{2}$. This range covers a wide range of possible subgrade soils with different strength. 
TABLE 4: Design parameters for developing design charts.

\begin{tabular}{|c|c|c|c|c|c|}
\hline Parameter & Value & Parameter & Value & Parameter & Value \\
\hline$a_{\mathrm{AC}}$ & 0.44 & $E_{\text {Base }}$ & $1960 \mathrm{~kg} / \mathrm{cm}^{2}$ & $\mathrm{Q}_{\mathrm{TC}}$ & $0.5 \mathrm{~kg} / \mathrm{m}^{2}$ \\
\hline$a_{\mathrm{ATB}}$ & 0.32 & $E_{\text {Subbase }}$ & $1050 \mathrm{~kg} / \mathrm{cm}^{2}$ & $\min _{d_{\mathrm{AC}}}$ & Table 2 \\
\hline$a_{\mathrm{GB}}$ & 0.13 & $P_{i}$ & 4.2 & $\min _{d_{\mathrm{GB}}}$ & Table 2 \\
\hline$a_{\mathrm{GB}}$ & 0.13 & $P_{t}$ & Table 1 & $\min _{d_{\mathrm{SGB}}}$ & $15 \mathrm{~cm}$ \\
\hline$S_{0}$ & 0.35 & $Z_{R}$ & Table 1 & $\min _{d_{\mathrm{ATB}}}$ & $7.5 \mathrm{~cm}$ \\
\hline
\end{tabular}

Drainage coefficient for all layers is assumed to be equal to 1 .

TABLE 5: Construction cost for different materials [26].

\begin{tabular}{lcc}
\hline Layer & Unit & Unit cost (Rials) \\
\hline Asphalt concrete & $1 \mathrm{~m}^{2}$ per cm thickness & 18500 \\
Asphalt treated base & $1 \mathrm{~m}^{2}$ per cm thickness & 15800 \\
Granular base & $\mathrm{m}^{3}$ & 149700 \\
Granular subbase & $\mathrm{m}^{3}$ & 84900 \\
Tack coat & $\mathrm{kg}$ & 15600 \\
\hline
\end{tabular}

At this time $1 \$ \cong 30000$ Rials.

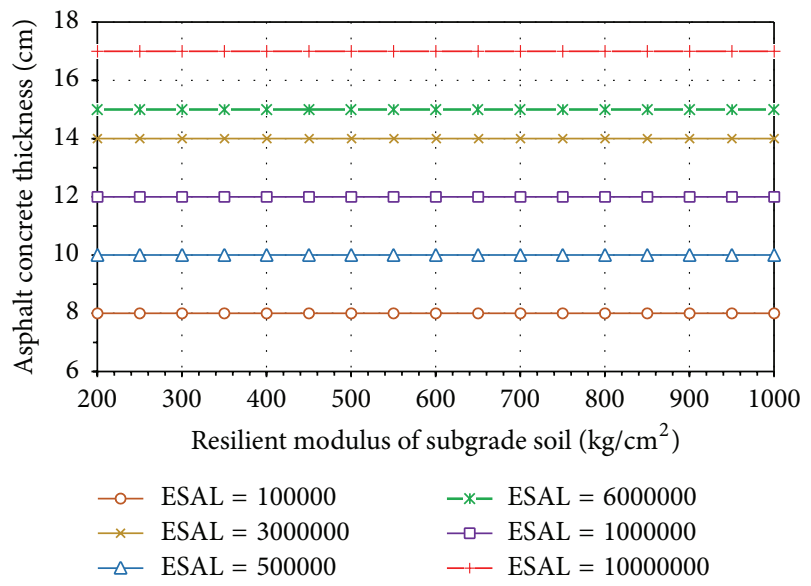

FIGURE 2: Optimal design thickness of asphalt concrete for secondary rural roads.

Also, the number of equivalent single axle loads (ESALs) or $W_{8.2}$ was assumed as $10^{5}, 5 \times 10^{5}, 10^{6}, 3 \times 10^{6}, 6 \times 10^{6}$, and $10^{7}$ which can reflect light to heavy traffic.

The results of determining the optimum thickness of each layer of pavement, with respect to the road classification are shown in Figures 2-10. In all cases, the thickness of asphalt treated layer is equal to zero, which indicates the fact that, in the current situation (material prices based on "Basic Price List for Road, Runway and Railway" in 2015), use of asphalt treated base layer in pavement structure is not cost effective. Also, with increasing the strength of subgrade soil, the granular subbase layer may be removed from the optimum structure of pavement. The possibility of removing the granular subbase layer increases by decreasing design traffic and increasing subgrade strength. For example in case of major roads with an ESALs of $1 \times 10^{6}$ and $10^{7}$, when

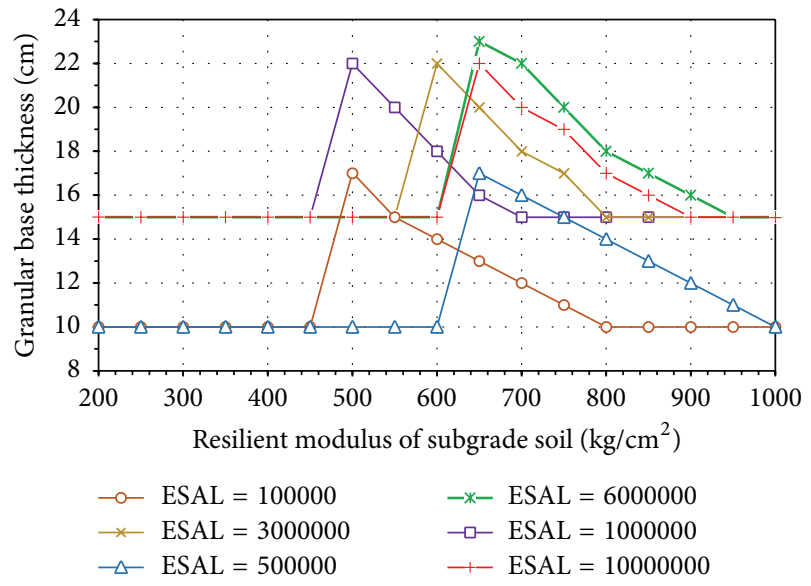

FIGURE 3: Optimal design thickness of granular base for secondary rural roads.

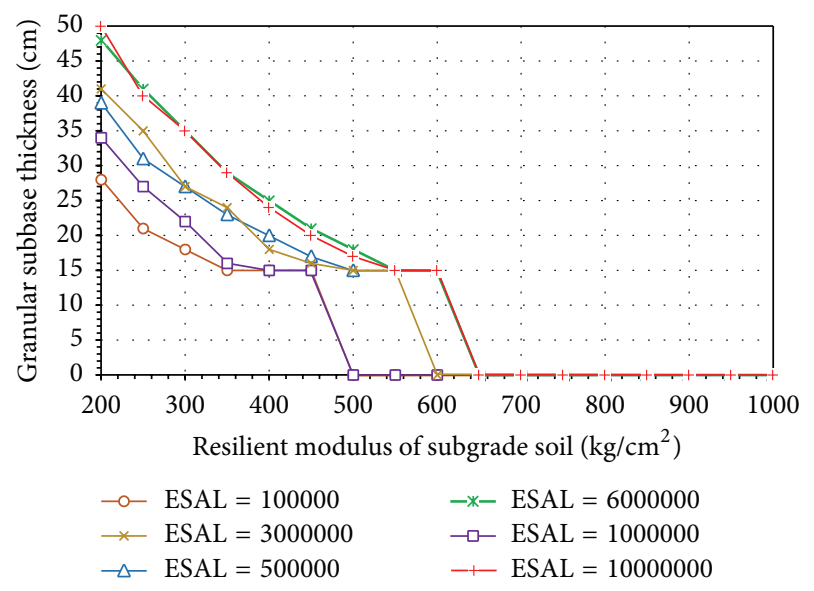

FIGURE 4: Optimal design thickness of granular subbase for secondary rural roads.

resilient modulus of subgrade exceeds 500 and $700 \mathrm{~kg} / \mathrm{cm}^{2}$, respectively, the granular subbase layer is removed from the optimum structure of pavement.

According to road classification, design traffic, and resilient modulus of subgrade, Figures 2-10 can be used to determine the optimum thickness of pavement layers including asphalt concrete, granular base, and granular subbase. 


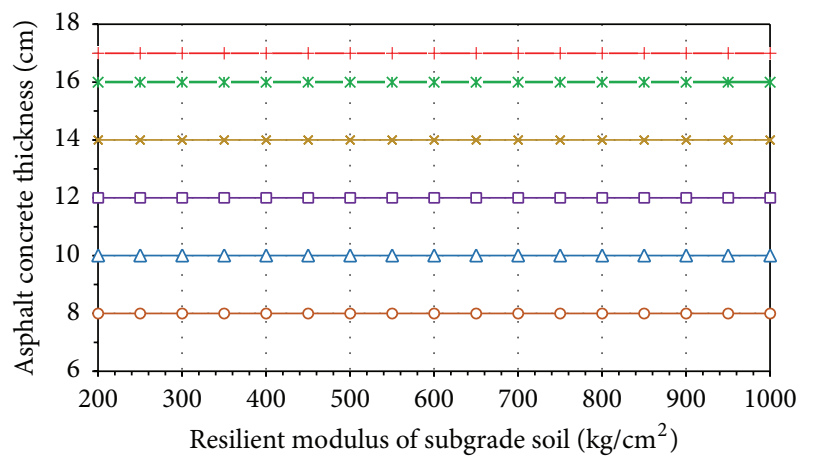

$\begin{array}{ll}\multimap \text { ESAL }=100000 & -*-\text { ESAL }=6000000 \\ \rightarrow \text { ESAL }=3000000 & -\square \text { ESAL }=1000000 \\ \rightarrow-\mathrm{ESAL}=500000 & -\leftarrow \text { ESAL }=10000000\end{array}$

Figure 5: Optimal design thickness of asphalt concrete for major rural roads.

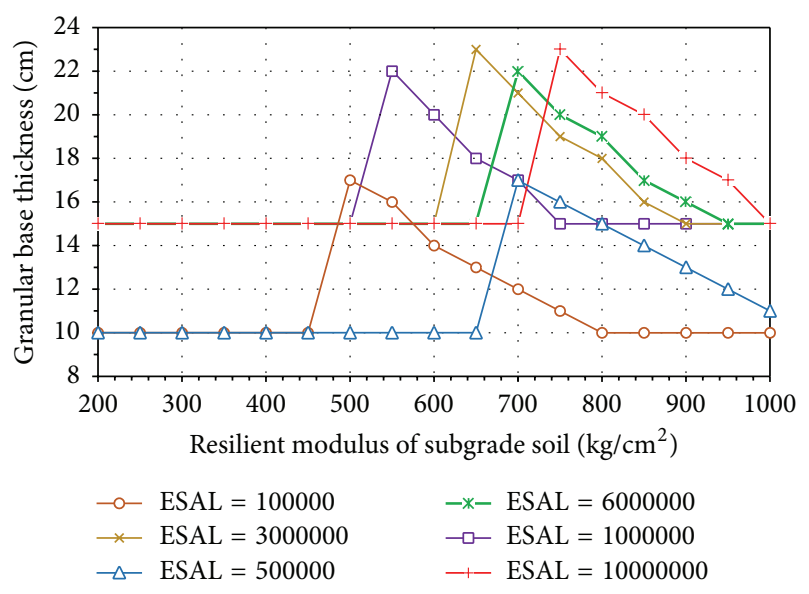

FIGURE 6: Optimal design thickness of granular base for major rural roads.

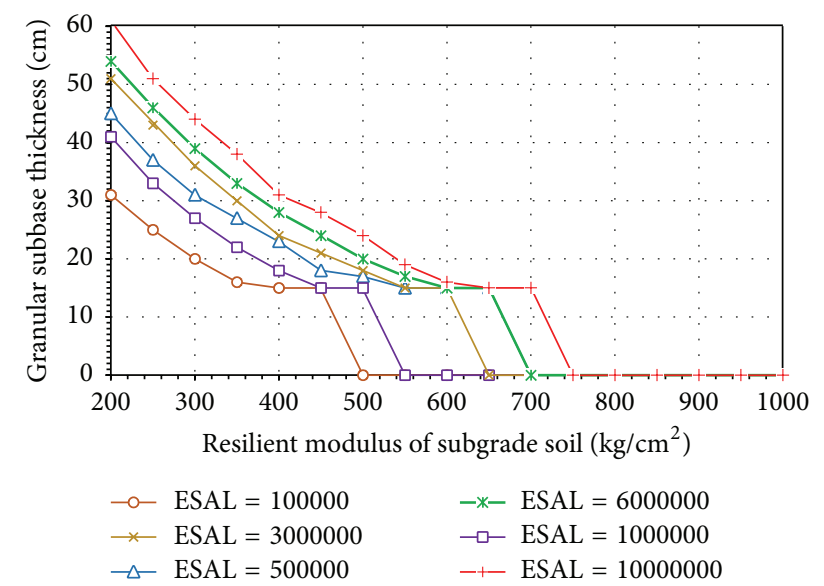

FIgURE 7: Optimal design thickness of granular subbase for major rural roads.

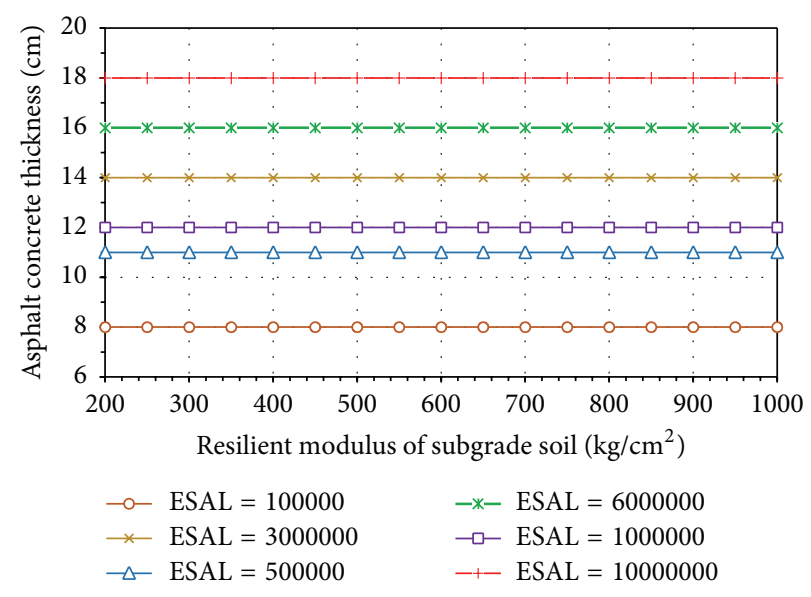

FIGURE 8: Optimal design thickness of asphalt concrete for expressways and freeways.

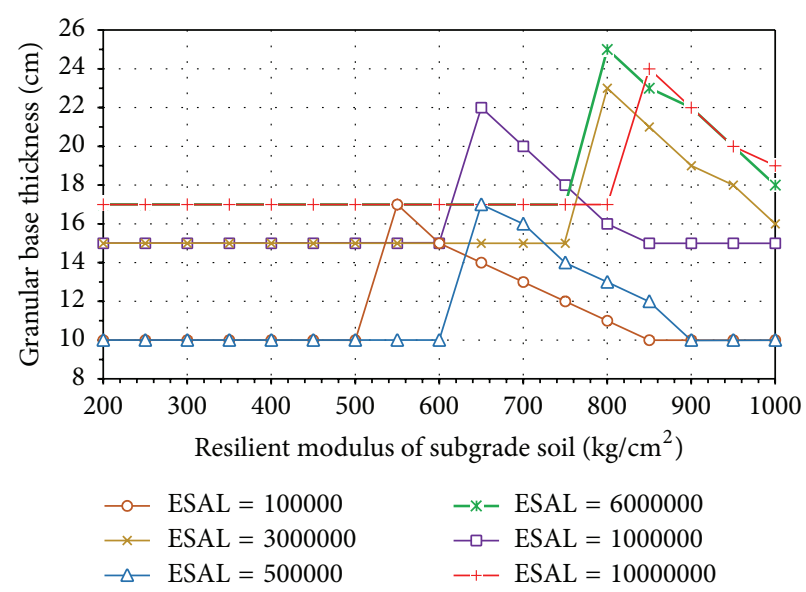

FIGURE 9: Optimal design thickness of granular base for expressways and freeways.

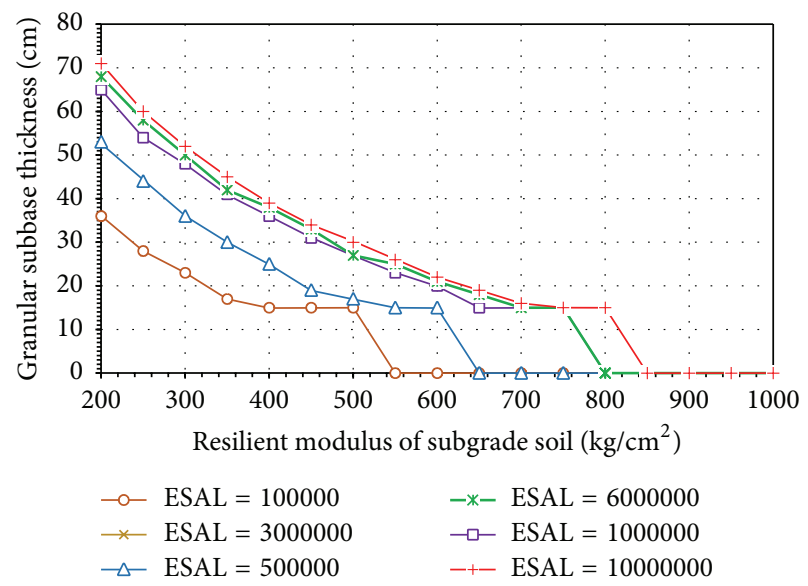

FIgURE 10: Optimal design thickness of granular subbase for expressways and freeways. 


\section{Conclusion}

In this paper an optimization model was proposed to determine the optimal configuration as well as the optimum thickness of each layer of pavement structure based on the Iran Highway Asphalt Paving Code 234. By utilizing the proposed optimization model and according to the "Basic Price List for Road, Runway and Railway" of Iran in 2015, the optimum thickness of pavement layers for secondary rural roads, major rural roads, and freeways were determined and then design charts were developed. Developed charts help designers to determine the optimum thickness of pavement layers including asphalt concrete, granular base, and granular subbase with respect to road classification, design traffic, and resilient modulus of subgrade. This study showed that in the current situation (material prices in 2015), use of asphalt treated layer in pavement structure is not cost effective. Also it was shown that, with increasing the strength of subgrade soil, the granular subbase layer may be removed from the optimum structure of pavement.

\section{Conflict of Interests}

The author declares that there is no conflict of interests regarding the publication of this paper.

\section{References}

[1] R. Mallick and T. El-Korchi, Pavement Engineering: Principles and Practice, CRC Press, New York, NY, USA, 2013.

[2] Y. H. Huang, Pavement Analysis and Design, Prentice Hall, New York, NY, USA, 2nd edition, 2004.

[3] C. L. Monismith, K. E. Secor, and W. Blackmer, "Asphalt mixture behaviour in repeated flexure," in Proceedings of the Association of Asphalt Paving Technologists, vol. 30, pp. 188-222, 1961.

[4] G. M. Dorman, "The extension to practice of a fundamental procedure for design of flexible pavements," in Proceedings of the 1st International Conference of Structural Design of Asphalt Pavements, pp. 785-793, Ann Arbor, Mich, USA, 1962.

[5] Austroads, Guide to Pavement Technology-Part 2: Pavement Structural Design, Austroads, Sydney, Australia, 2010.

[6] NCHRP, "Mechanistic-empirical design of new \& rehabilitated pavement structures," NCHRP 1-37A, 2008.

[7] IRC, Guidelines for the Design of Flexible Pavements, 3rd Revision, Indian Road Congress, New Delhi, India, 2012.

[8] Shell International Petroleum Company Limited, Shell Pavement Design Manual-Asphalt Pavements and Overlays for Road Traffic, London, UK, 1978.

[9] H. Theyse, J. Maina, and L. Kannemeyer, "Revision of the South African flexible pavement design method; mechanisticempirical components," in Proceedings of the 9th Conference on Asphalt Pavements for Southern Africa (CAPSA '07), Gaborone, Botswana, 2007.

[10] The Asphalt Institute, Thickness Design-Asphalt Pavements for Highways and Streets, Manual Series No. 1 (MS-1), The Asphalt Institute, 9th edition, 1999.

[11] LCPC and SETRA, French Design Manual for Pavement Structures, Guide Technique, Union des Syndicats de l'Industrie Routière Française, 1997.
[12] American Association of State Highway Official, AASHTO Guide for Design of Pavement Structures, American Association of State Highway Official, Washington, DC, USA, 1993.

[13] Japan Road Association, Manual for Asphalt Pavement, Japan Asphalt Association, 1989.

[14] HMSO, "A guide to the structural design for new roads," Tech. Rep. RN-29, Department of the Environment, London, UK, 1970.

[15] Iran Management and Planning Organization, Iran Highway Asphaltic Pavements (IHAP) Code, vol. 234, Tehran, Iran, 2nd edition, 2010.

[16] N. M. Rouphail, "Minimum-cost design of flexible pavements," Journal of Transportation Engineering, vol. 111, no. 3, pp. 196-207, 1985.

[17] R. Nicholls, "Optimization of AASHTO DNPS86 pavement design program," Journal of Transportation Engineering, vol. 117, no. 2, pp. 189-209, 1991.

[18] M. S. Mamlouk, J. P. Zaniewski, and W. He, "Analysis and design optimization of flexible pavement," Journal of Transportation Engineering, vol. 126, no. 2, pp. 161-167, 2000.

[19] L. Mu-yu and W. Shao-yi, "Genetic optimization method of asphalt pavement based on rutting and cracking control," Journal of Wuhan University of Technology, vol. 18, no. 1, pp. 7275, 2003.

[20] K. A. Abaza and S. A. Abu-Eisheh, "An optimum design approach for flexible pavements," International Journal of Pavement Engineering, vol. 4, no. 1, pp. 1-11, 2003.

[21] Y. Ouyang and S. Madanat, "Optimal scheduling of rehabilitation activities for multiple pavement facilities: exact and approximate solutions," Transportation Research Part A: Policy and Practice, vol. 38, no. 5, pp. 347-365, 2004.

[22] M. Fakhri and A. R. Ghanizadeh, "Optimization of pavement design in AASHTO method by means of a linear programming model," Quarterly Journal of Transportation Research, vol. 1, no. 1, pp. 77-89, 2004.

[23] M. Sanchez-Silva, O. Arroyo, M. Junca, S. Caro, and B. Caicedo, "Reliability based design optimization of asphalt pavements," International Journal of Pavement Engineering, vol. 6, no. 4, pp. 281-294, 2005.

[24] P. Rajbongshi and A. Das, "Optimal asphalt pavement design considering cost and reliability," Journal of Transportation Engineering, vol. 134, no. 6, pp. 255-261, 2008.

[25] J. Santos and A. Ferreira, "Pavement design optimization considering costs and M\&R interventions," Procedia-Social and Behavioral Sciences, vol. 53, pp. 1182-1191, 2012.

[26] Iran Management and Planning Organization, Basic Price List for Road, Runway and Railway, Iran Management and Planning Organization, Tehran, Iran, 2013. 


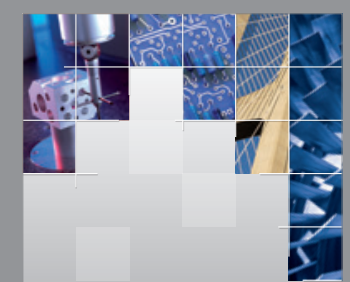

\section{Enfincering}
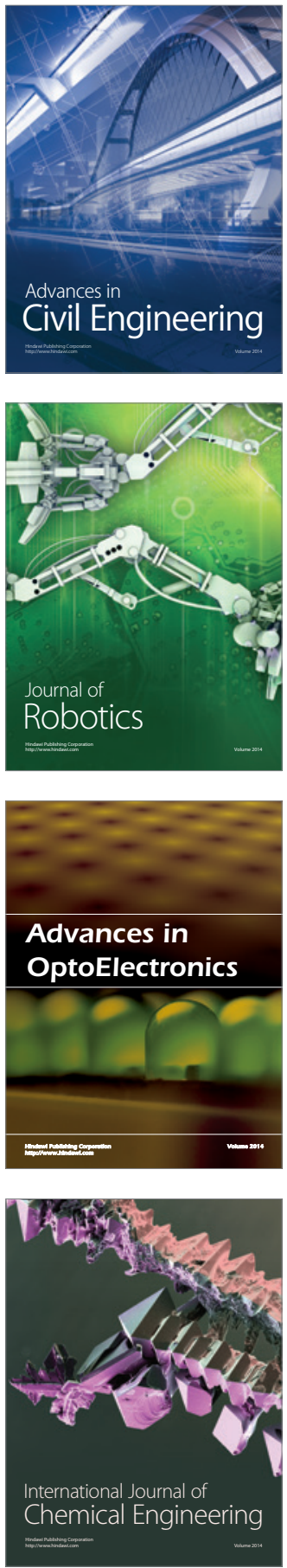

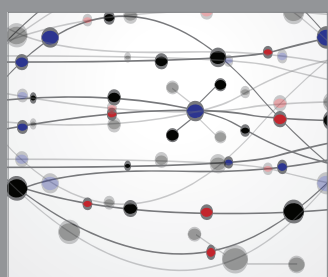

The Scientific World Journal

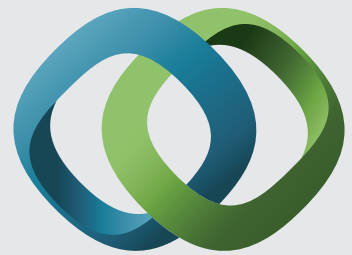

\section{Hindawi}

Submit your manuscripts at

http://www.hindawi.com
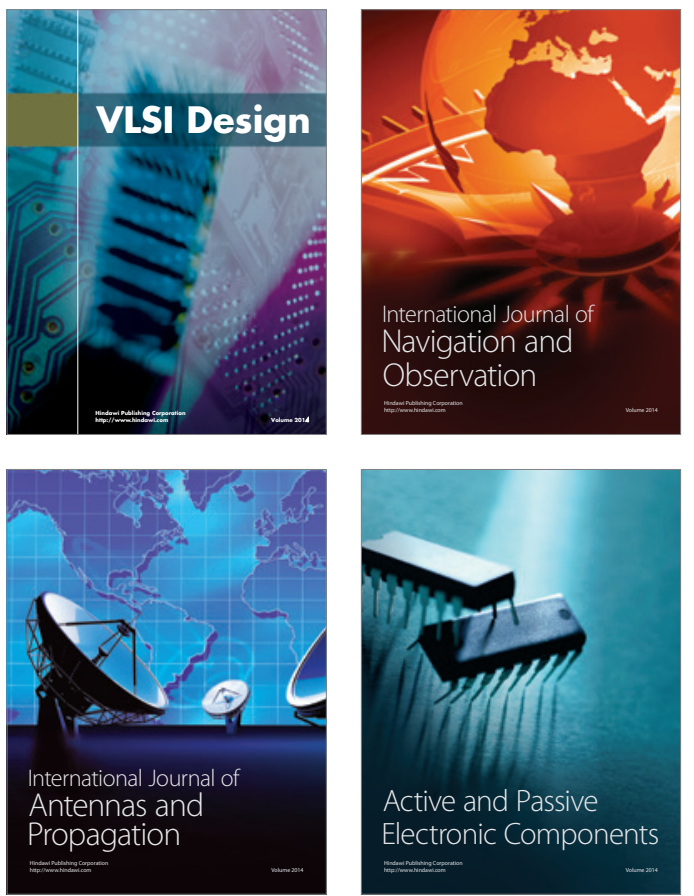
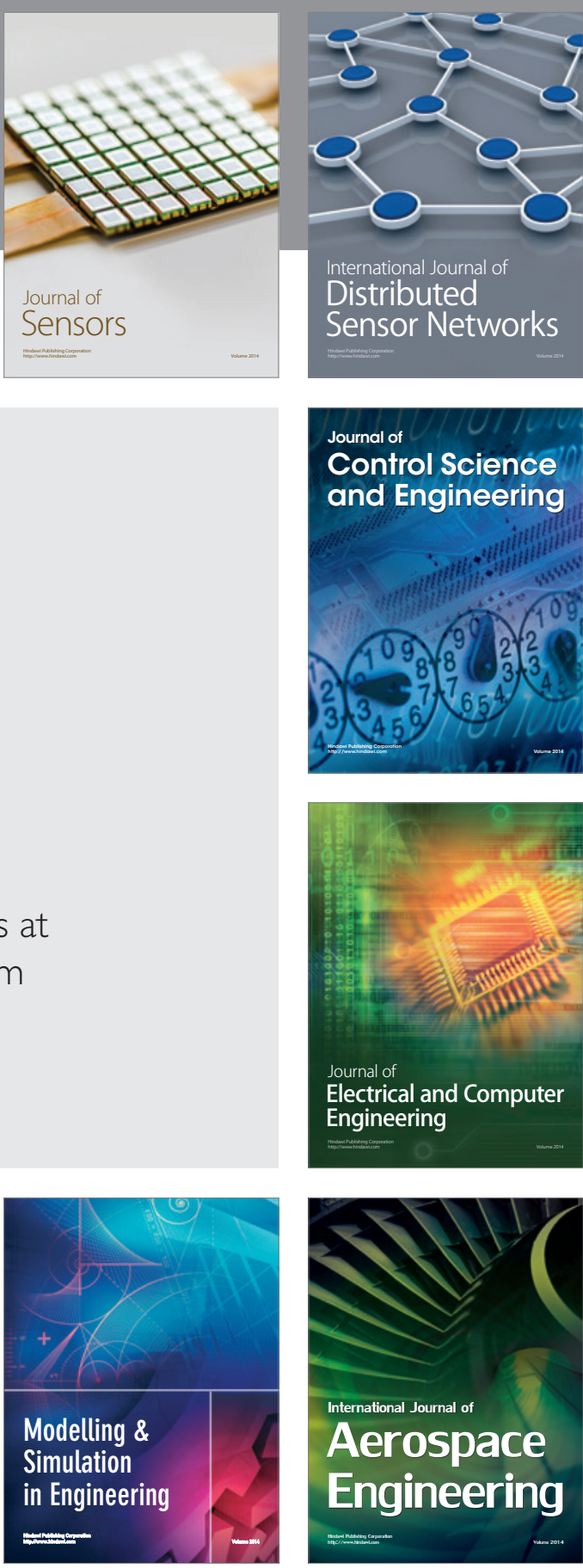

International Journal of

Distributed

Sensor Networks

Journal of

Control Science

and Engineering
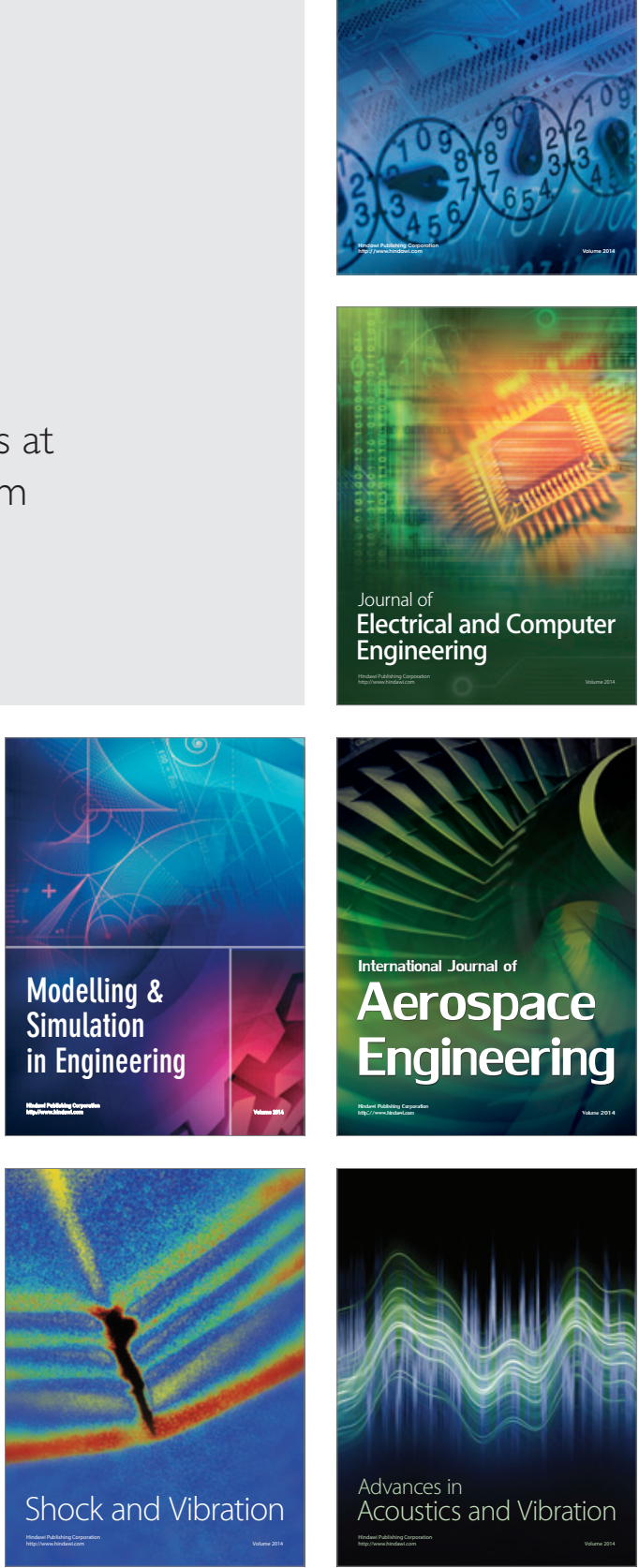